\title{
Raising Awareness of Sexual Abuse among Children with Intellectual Disabilities: A Survey of Teachers' Views
}

\author{
Suad M.O. Abuzaid ${ }^{*}$
}

\author{
Taibah University, Special Education, Saudi Arabia
}

\begin{abstract}
Sexual abuse is one of the most dangerous phenomena that can overwhelm any society. Children with ID seem to be among the groups with the highest risks for sexual abuse/maltreatment. This research aims to investigate teachers' views regarding how raising awareness of sexual abuse among children with intellectual disabilities. This phenomenon is not spared even the mentally handicapped, as they may not realize the extent of the abuse they are exposed to and may not tell anyone about it, because they do not understand it, they may not realize the standards of religion, society, and standards of social behavior. The sample was 40 teachers of children with intellectual disabilities from Madina El Monawara. This study utilized a qualitative research technique. To collect data, a semi-structured interview method was employed. In response to some big questions: What causes for high prevalence rates of sexual abuse in individuals with ID? How to raise children with intellectual disabilities' awareness of Sexual Abuse? According to teachers' views, lack of social skills, lack of sexual knowledge, inequality in relationships, and the fact that in some cases, individuals with ID need to depend on others were the main causes. Educating children with ID to say no to bad touches, getting to report being victims of sexual abuse, getting them to understand what sexual abuse is or that sexual abuse is a crime, not to be afraid of repercussions they may face from their abuser, or feel ashamed, embarrassed, or blame themselves for the abuse are the most frequently reported recommendations to raise children with intellectual disabilities' awareness of Sexual Abuse.
\end{abstract}

Keywords: Awareness, children, intellectual disabilities, sexual abuse, teachers' views.

\section{INTRODUCTION}

Intellectual disability (ID) is one of the disabilities that exist in all societies. Statistics indicate that about 3.5 per thousand suffer from some form of mental disability in the age group of 10-14 years, and this percentage increases to reach about 6 per thousand in all other age groups. The categories of the mentally disabled have been multiplied to facilitate detecting them and identifying their characteristics and how to deal with them in a way that helps them make good use of their mental capabilities [1-7].

Intellectual disability (ID) results from a defect in the higher functions of the brain such as concentration, counting, memory, communication with others and others, which result in educational disabilities, learning difficulties, or defects in the behavior and general behavior of the individual, and it also falls under the concept of mental disability (Intellectual disability learning difficulties - autism disorder). Psychologists, scholars of special education, psychiatry, and others differ in determining the causes of mental disability, as most research and studies indicate that the causes vary between genetics, injuries, physical factors, brain diseases, disorders of endocrine secretion, malnutrition diseases, pregnancy, and childbirth disorders, environmental factors and the psychological state of the mother during pregnancy [3].

*Address correspondence to this author at the Taibah University, Special Education, Saudi Arabia; E-mail: sabuzaid@taibahu.edu.sa
There are many causes for this disability. These can be categorized as follows. Prenatal causes: They are limited to genetic factors, diseases affecting the pregnant mother, large or small skull, exposure to radiation, drugs, and medications, cases of plasma poisoning, metabolic and nutritional disorders, air and water pollution, $\mathrm{Rh}$ factor variation, in addition to injuries and malignant tumors. Causes during childbirth: These include difficult labor, meningitis, physical trauma, and abnormal delivery. Postpartum causes: These include malnutrition, infections, diseases, iodine deficiency, lack of oxygen after childbirth, poisoning by pollutants, as well as severe brain diseases [1].

Physical characteristics: The intellectually disabled is characterized by delayed and slow physical growth and small size in general, and their weight is less than normal, and the size of the brain is smaller, and the weight of the mentally disabled is less than the average, and sometimes deformations may appear in the shape of the skull, eyes, mouth, limbs, and fingers. As for motor growth, they are characterized by a delay in that and motor imbalance in some cases, as well as for sexual activity, where we find a delay in it, and sometimes we find atrophy in the genitals of the injured [1].

Mental characteristics: The mental characteristics of the intellectually disabled in general are summarized in delayed cognitive development and low IQ to less than 70 degrees, in addition to the delay in language 
development to a large extent, as well as concerning other mental processes such as poor memory, attention, perception, imagination, thinking, ability to understand, judge and ability to comprehend, and the result of this is a poor achievement and a lack of information and experience [8].

Social characteristics: The intellectually disabled are characterized by poor social adaptability to the extent that some psychologists have called for social adaptability to be taken as a basis in classifying the mentally retarded into categories according to their abilities to adapt, and of course, there is a great disparity between these groups in the ability to social adapt, but generally In general, we find that the mentally disabled are characterized by a lack of tendencies and interests and a lack of responsibility, as they are characterized by withdrawal and aggressiveness, in addition to the disorder of their selfconcept, where we find that the mentally disabled often views himself as a failure or helpless and that he is less than others or has no value this turbulent concept is reflected a very large extent on his social behavior in particular and his interest in his self-hygiene as well. We find that he does not care about forming social relationships, especially with his children, and tends to participate with those younger than him in any social practices $[1,3,9]$.

The intellectually disabled suffer from a clear lack of attention and discriminatory learning regarding shapes, colors, and situations, especially among the moderate and severe mental handicap categories. The intellectually disabled, especially the moderate and severe mental handicap group, also suffer from frustration and a feeling of failure. They try to focus on the teacher's facial expressions more than on the task required of them. In addition, the intellectually disabled suffer from the stage of receiving information in the hierarchy of the processes or stages of learning and remembering, so the special education teacher needed to focus on the steps of learning and remembering and work to help mentally disabled children receive information in an orderly manner [1,10-14].

Sexual abuse is one of the most dangerous phenomena that can invade any society, and it is one of the things that happen in the whole world without exception to our Arab countries. That talk about it is still a silent issue. Sexual abuse is a phenomenon that does not threaten the loss of females, but it has become a widespread issue in society. The mentally disabled girls did not escape from them. What increases the severity of the particular group's exposure to sexual harassment is that the mentally disabled do not realize the extent of the abuse she is exposed to and may tell. No one, because she does not understand this, does understand the standards of religion and society and the controls of social behavior [15]. In comparing children with Id to their non-disabled peers, they are likely to be at higher risk of experiencing sexual abuse victimization [16].

The sexual development of the disabled is not different from the sexual development of their normal peers, although there are some problems they have in understanding and interacting with sex. Nevertheless, the concept of parents and some specialists and society sometimes is still linked to some misconceptions based on which they refuse to recognize the right of the intellectually disabled In expressing their sexual desires, they perceive that they are unable to control their sexual desires responsibly. They cannot understand and comprehend information about sexuality [17].

The most important misconceptions based on which they reject the rights of the sexually disabled are represented in the following elements [18]:

1- They are uninterested in sex and sexually incapable.

2- $\quad$ They lose the ability to understand and process information about sex, and to control their sexual desires responsibly.

3- That they have enough difficulties not to risk sexual relations.

4- $\quad$ They will have children like themselves and are unable to take care of children like themselves.

The intellectually disabled children and adolescents usually show unacceptable behavior patterns in the social sphere and suffer from a weak will, so it is easy for them to be subjugated to others without resistance perverted. These characteristics and traits qualify them to be more vulnerable than their ordinary peers to sexual abuse and exploitation. However, there is an apparent discrepancy in these characteristics and features between the different levels of mental disability. Sexual abuse has multiple forms of sexual abuse that ends with the whole sexual process [19-20].

\section{Aims of the Study}

The present study is designed to determine perceptions regarding teachers' views of how to raise 
awareness of Sexual Abuse among children with ID and the causes for high prevalence rates of sexual abuse in individuals with ID.

\section{Problem Statement}

Sexual abuse is one of the biggest threats to human life in society and may lead to death or suicide in the most severe cases. He moves a finger. This crime against humanity threatens existence and turns society into a jungle of savages, dishonorable and lacking in chivalry and feeling. Child sexual abuse is a health, psychological, and social problem that has serious repercussions on child victims, victims' families, and society. The researcher inferred the current research problem by noting a large number of media abuse of children, including sexual abuse. This study seeks to give answers to the two main questions.

1. What are the causes for high prevalence rates of sexual abuse in individuals with ID?

2. How to raise children with intellectual disabilities' awareness of Sexual Abuse?

\section{METHODS}

This study seeks to answer the two main questions: What are the causes for high prevalence rates of sexual abuse in individuals with ID? How to raise children with intellectual disabilities' awareness of Sexual Abuse? Data were collected from teachers online via Zoom App.

\section{Participants}

To recruit the study participants, the researcher adopted a purposeful sampling technique. This involves teachers of children with intellectual disabilities. The researcher was helped with the participant selection process by providing the contact details of those selected teachers. The researcher was then able to contact teachers via e-mail and telephone for possible interest and participation in this study. 40 teachers responded by e-mail, expressing their willingness to join in the research.

\section{Data Collection Procedure}

The data for this research study were collected using qualitative data method including, mainly, interviews which provided insights into teacher's points of view regarding how to raise awareness of sexual abuse among children with intellectual disabilities.

\section{Interview Process}

After establishing initial contact with participants, the researcher began to interview them via Zoom App. All interviews were audio- and video recorded, and participants reaffirmed consent verbally prior to the interviews. Interviews focused on participants' views regarding how to raise awareness of Sexual Abuse among children with intellectual disabilities. The length of the interviews was 4 hours, with some intervals. Participants were given a copy of the interview schedule so that they could feel more at ease. The contents of the notes were verbally reviewed with the interviewee for clarity and accuracy.

\section{Validity and Reliability of Interviews}

Two methods were employed to ensure the validity of the interviews, namely, interview questions and researcher bias. The researcher designed the interview questions and structured them after conducting the literature review on the topic and consulting with experts in the field. The researchers did their best to minimize personal bias as much as possible. The author used text analytics software (Thematic) to analyze participants' feedback for automated qualitative data analysis.

\section{Ethical Approval}

Participants received letters informing them of the study and requesting consent. The letter stated that the data and information collected will be kept confidential and anonymous. Participants signed electronically consent forms ensuring the respondents' confidentiality, privacy, and anonymity, respecting the ethical principles of scientific research.

\section{FINDINGS FROM THE INTERVIEWS}

In order to help the reader get the picture of the study easily, the author added a sub-heading of each theme based on an important topic that was raised during the interview process.

\section{Causes for High Prevalence Rates of Sexual Abuse in Individuals with ID}

On responding to the question: What are the causes for high prevalence rates of sexual abuse in individuals with ID? Participants responded by giving different causes that can be grouped into the following :

"The main reason children with ID are sexually abused is that they are not 
interested in sex and are sexually incapable".

"In my opinion, it the unfamiliarity of children with ID with the prevailing social values, norms, and traditions".

"I agree with the opinions of my colleagues. However, I believe that among the main and important reasons that play a role in being victimized is the low mental abilities of the children with ID".

"As for me, I think poor communication with parents due to intellectual disability and language delay may be among the important reasons".

"I see that those children can be victims for more than one time because many of them do not report being victims of SA as they are afraid of repercussions they may face from their abuser, or they feel ashamed, embarrassed, or blame themselves for the abuse".

"As a matter of fact, individuals with ID are independent persons, that is, they need to depend on others because of the inequality in relationships".

"In fact, my colleague raised a critical point about the reason for the frequent exposure to sexual abuse in this group of children. Some children may not report being victims of sexual abuse because they may not understand what sexual abuse is or that sexual abuse is a crime".

\section{How to Raise Children with Intellectual Disabilities' Awareness of Sexual Abuse?}

On responding to the question: How to raise children with intellectual disabilities' awareness of Sexual Abuse? Participants responded by giving different methods that can be grouped into the following :

"there should be programs that aim to improve knowledge and skills in individuals with MID in order to reduce risk of potential sexual abuse".

"I think, educators should Implement policies that increase the physical and psychological safety and security of the disabled, for example, studying the history of new employees who join work in institutions for the care and education of the disabled, in addition to excluding those who suspect that they may engage in abusive behaviors from work in such institutions".

"As for me, I think educators should Actively address the fact that people with intellectual and other developmental disabilities are more vulnerable to sexual abuse than their non-disabled peers".

"Ah, yes. Well. The effective way to reduce the harmful effects of sexual harassment of children is through prevention and early detection to start the treatment process".

"Well. Child sexual abuse prevention programs create environments in which children are able to speak up before any form of abuse. Taking into account the prevalence of sexual harassment of children and its consequences for the victim, prevention and awareness programs have been prepared and implemented on a large scale ".

"Yes, preventive interventions aim to enable children to recognize abusive situations and teach them strategies such as saying "no" or yelling, and encouraging them to disclose the abuse (sexual abuse) to a trusted adult".

"The video entitled "Believe Me", a 12minute animated video for a group of children aged 9-13 years, is shown to individuals in affirmative and challenging situations. This video explores the disasters small people face if they talk to older people".

\section{DISCUSSION}

The present study is designed to determine perceptions regarding teachers' views of how to raise awareness of sexual abuse among children with ID and the causes for high prevalence rates of sexual abuse in individuals with ID. Sexual abuse or sexual harassment is exposure to a person, either by directing immoral 
words that contain inappropriate sexual innuendos, or by touching him in different areas of his body, especially the genitals, or by having sexual intercourse with him directly, and all of these behaviors are against the victim's consent.

The most vulnerable group to sexual harassment is children, especially the disabled because they cannot defend themselves. The Arab media rarely publish sexual abuse against the disabled, especially the male ones, because sexual abuse has been associated in Arab societies with the loss of the hymen, although research confirms that people with special needs are more likely to be sexually abused compared to their healthy counterparts. The desire of the disabled, social integration, and lack of awareness makes him an easy victim of sexual exploitation. In addition, some disabled people cooperate and accept harassment to satisfy their curiosity and sexual instinct. Among the factors that facilitate the exposure of disabled people to sexual abuse: the harasser's reassurance that the disabled are unable to report, in addition to that some disabled people are unable to In addition to the ignorance of the disabled about the methods and methods of sexual abuse, the disabled's dependence on the harasser in terms of treatment and all other matters makes it easier for the harasser to conceal his crime, and the lack of mutual interest and affection between parents and the disabled may make him accept any aspect of good and friendship even if this leads to establishing a perfect sexual relationship.

People with intellectual disabilities may not realize that what they are exposed to from sexual abuse is actually abusive, homosexual, illegal or illegal, and therefore they may not tell anyone at all about what they are exposed to in sexual abuse situations and in general, people with disabilities or non-disabled people. People who are afraid to speak openly about such traumatic experiences as a result of their fear that they will not be believed or that their words will not be taken seriously usually learn not to doubt their caregivers or other symbols or sources of authority. Sadly, the sources of It are these trusted authority figures who perpetrate this abuse, and Turnbull et al. [21] point to another factor in many educational programs that encourages students to submit to a wide range of life activities.

This study is in the same line with Sobsey and Doe [22] in Australia, who confirmed that that person with developmental and cognitive problems (i.e., suffering from ID, autism, cerebral palsy, epilepsy, and learning disabilities) was sexually assaulted 10.7 times more than non-disabled individuals. Victims who have some degree of intellectual impairment are at the highest risk of abuse [22].

Building on the findings presented here, there is a need to develop programs further to see whether these are helpful in preventing sexual abuse among children with ID. Children with ID should be educated to say no to bad touches, report being victims of sexual abuse, understand what sexual abuse is or that sexual abuse is a crime, not to be afraid of repercussions they may face from their abuser, or feel ashamed, embarrassed, or blame themselves for the abuse.

Child sexual abuse prevention programs create environments in which children are able to speak up before any form of abuse [23]. Taking into consideration the prevalence of sexual abuse of children and its consequences for the victim. In addition, the use of multimedia to raise awareness against sexual harassment of children is an essential factor in educating people on this issue, as research projects have proven the effectiveness of technology in educating children by watching others and imitating the observed behavior [24]. The literature also indicated that technology such as video is a valuable material that helps young people and others reflect on some fundamental elements of knowledge about sexual abuse of children [25].

\section{CONCLUSIONS}

It can be summarized that The most vulnerable group to sexual harassment is children, especially the disabled, because they are entirely unable to defend themselves. The Arab media rarely publish news of sexual abuse against the disabled, especially the male ones, because sexual abuse has been associated in Arab societies with the loss of the hymen. However, research confirms that people with special needs are more likely to be sexually abused than their healthy counterparts. However, there are some limitations. For instance, the number of the research population is limited, only 40 teachers. Future research needs to widen the scope to include more participants. Second, this research study relied on a qualitative method in collecting data. Future research needs to use different methods, especially mixed methods. Third, this research study included only female children. Future research needs to be applied to both sexes. More studies are required in order to understand the phenomenon better. 
A disabled girl, in particular, may be used in sexual activities that she cannot realize, as she cannot refuse or accept them. A disabled girl may get used to such activities in the complete absence of her family, where the offender (the harasser) follows one of two ways: Either intimidation of the disabled girl who is powerless, or the harasser takes another method, which is to entice the victim, such as giving the disabled girl gifts and sweets and exploiting her lack of awareness and awareness of religious laws, moral controls, and societal standards. This comes from the inability to control the instinct, which it does not understand but achieves emotional pleasure, so it is necessary to look for the following physical signs when children are mentally disabled. Unexplained pregnancy (in the case of a girl), disturbing the genitals resulting in sexual provocation and bleeding in the genital areas. Difficulty walking (as this could be a sign of anal penetration). Attempting to help a person with intellectual disability to distinguish any stranger who deals with her, so that she does not initiate peace on anyone with whom she does not have a close relationship nor respond to that person or take anything from him that he offers her. She should understand that the evil person is not related to the ominous appearance of clothes. She only responds to people she knows well, such as her father, mother, and relatives.

\section{ACKNOWLEDGEMENT}

The author wishes to thank teachers who agreed to participate with their views on this study.

\section{REFERENCES}

American Psychiatric Association. Diagnostic and statistical manual of mental disorders. Washington DC: APA 2013; 51.

Bartnikowska U, Ćwirynkało K, and Borowska-Beszta B. A pattern of transition to adulthood indicated in plans for the future of males with intellectual disabilities: secondary qualitative data analysis. Psycho-Educ Res Rev 2017; 6(1): 51-56. https://www.journals.lapub.co.uk/index.php/perr/ article/view/159.

[3] Eissa M, ElAdl A. Defining and determining intellectual disability (intellectual developmental disorder): insights from5. Psycho-Educ Res Rev 2019; 8(1): 51-54. https://www. journals.lapub.co.uk/index.php/perr/article/view/352

[4] Al-Said A. The effectiveness of a phonological awareness training intervention on phonological working memory of children with intellectual disabilities. Psycho-Educ Res Rev 2014; 3(1): 50-55. https://www.journals.lapub.co.uk/ index.php/perr/article/view/230.

[5] Baczała D. Social skills of individuals with intellectual disabilities. Psycho-Edu Res Rev 2016; 5(2): 68-72.

[6] Eissa $M$. Issues related to identification of children with autism spectrum disorders (ASDS): insights from DSM-5. Psycho-Educ Res Rev 2018; 7(3): 62-66. https://www.journals.lapub.co.uk/index.php/perr/article/view/2 83.
[7]

El Sayed E. Effectiveness of a pivotal response-training programme in joint attention and social interaction of kindergarten children with autism spectrum disorder. PsychoEduc Res Rev 2019; 8(2): 48-56. https://www.journals.lapub. co.uk/index.php/perr/article/view/1164

[8] Hasanin $\mathrm{H}$. The effect of social information processing model training on improving social behaviour of with intellectual disabilities. Psycho-Educ Res Rev 2015; 4(1): 10 -22. https://www.journals.lapub.co.uk/index.php/perr/article/view/1 19

[9] Ćwirynkało K, Beata B, and Urszula B. Masculinity as defined by males self-advocates with intellectual disabilities: a focus group research report. Psycho-Educ Res Rev 2016; 5(3): 3650. https://www.journals.lapub.co.uk/index.php/perr/article/ view/152.

[10] Eissa $\mathrm{M}$ and Hesham $\mathrm{H}$. Effect of multisensory approach on increasing math skills children with mild intellectual disabilities. Psycho-Educ Res Rev 2013; 2(3):73-82. https://www.journals.lapub.co.uk/index.php/perr/article/view/2 23.

[11] Eissa M. Are Phonological awareness intervention programs effective for children with disabilities? A systematic review. Psycho-Educ Res Rev 2017; 6(3): 11 -22.

[12] Szczupał B. Incapacitation as a mean of protecting the dignity of the persons with disabilities in the view of convention on the rights of persons with disabilities. PsychoEduc Res Rev 2017; 6 (1): 1 -9. https://www.journals.lapub. co.uk/index.php/perr/article/view/155.

[13] Baczała D. Social skills of individuals with intellectual disabilities. Psycho-Educ Res Rev 2016; 5 (2): 68 -77 https://www.journals.lapub.co.uk/index.php/perr/article/view/1 39.

[14] Eissa $M$ and Borowska-Beszta B. Disability in the Arab world: a comparative analysis within culture. Psycho-Educ Res Rev 2019; 8(2): 29-47.

[15] Casey SE. Moving to prevent child sexual abuse: Dance/movement therapy as primary prevention. Am J Dance Ther 2018; 40: 240-253. https://doi.org/10.1007/ s10465-018-9286-4

[16] Stobbe KJ, Scheffers M, van Busschbach JT, and Didden R, Prevention and intervention programs targeting sexual abuse in individuals with mild intellectual disability: A systematic review. J Ment Health Res Intellect Disabil 2021; 14(2): 135158.

https://doi.org/10.1080/19315864.2021.1883780

[17] Kucuk S, Platin N, and Erdem E. Increasing awareness of protection from sexual abuse in children with mild intellectual disabilities: An education study. Appl Nurs Res 2017; 38(6): 153-158.

https://doi.org/10.1016/j.apnr.2017.10.016

[18] Lumley VA, Miltenberger RG, Long ES, Rapp JT, and Roberts JA. Evaluation of a sexual abuse prevention program for adults with mental retardation. J Appl Beh Anals 1998; 31(1): 91-101.

https://doi.org/10.1901/jaba.1998.31-91

[19] McCann E, Marsh L, and Brown M. People with intellectual disabilities, relationship, and sex education programmes: $A$ systematic review. Health Educ J 2019; 78(8): 885-900. https://doi.org/10.1177/0017896919856047

[20] Wissink IB, van Vugt ES, Smits IAM, Moonen XMH, and Stams G-JJM. Reports of sexual abuse of children in state care: A comparison between children with and without intellectual disability. J Intellect Dev Disabil 2018; 43(2): 152163. https://doi.org/10.3109/13668250.2016.1269881

[21] Turnbull H, Buchele-Ash A, and Mitchell L. Abuse and neglect of children with disabilities: A policy analysis. Lawrence, Kansas: Beach Center on Families and Disability, The University of Kansas 1994. 
[22] Sobsey D and Doe T. Patterns of sexual abuse and assault. Sex Disabil 1991; 9(3): 243-259. https://doi.org/10.1007/BF01102395

[23] Morano JP. Sexual abuse of the mentally retarded patient: Medical and legal analysis for the primary care physician. Primary Care Companion J Clin Psych 2001; 3(3): 126-135. https://doi.org/10.4088/PCC.v03n0304

[24] Peckham NG, Howlett S, and Corbett A. Evaluating a survivors group pilot for women with significant intellectual disabilities who have been sexually abused. J Appl Res Intellect Disabil 2007; 20(4): 308-322.

https://doi.org/10.1111/j.1468- 3148.2006.00347.x

[25] Soylu N, Alpaslan AH, Ayaz M, Esenyel S, and Oruç M. Psychiatric disorders and characteristics of abuse in sexually abused children and adolescents with and without intellectual disabilities. Res Dev Disabil 2013; 34(12): 4334-4342. https://doi.org/10.1016/..ridd.2013.09.010

Received on 01-01-2021

Accepted on 02-04-2021

Published on 01-06-2021

https://doi.org/10.6000/2292-2598.2021.09.03.9

(C) 2021 Suad M.O. Abuzaid; Licensee Lifescience Global.

This is an open access article licensed under the terms of the Creative Commons Attribution Non-Commercial License (http://creativecommons.org/licenses/by-nc/3.0/) which permits unrestricted, non-commercial use, distribution and reproduction in any medium, provided the work is properly cited. 